\title{
Fractionation and Distribution of Arsenic in Soils Contaminated by Cattle Dip
}

\author{
R. G. McLaren,* R. Naidu, J. Smith, and K. G. Tiller
}

\begin{abstract}
Soils surrounding cattle dips in Australia are known to be highly contaminated with As and are potentially of major concern to the environment and human health. A study of 11 dip sites in northern New South Wales (NSW) has revealed considerable surface soil (0-10

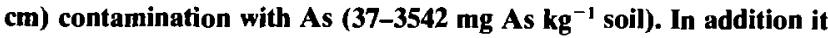
was shown that considerable movement of As down through the soils had occurred with concentrations at 20 to $40 \mathrm{~cm}$ ranging from 57 to

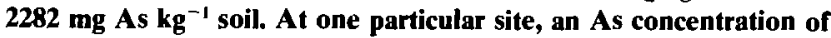

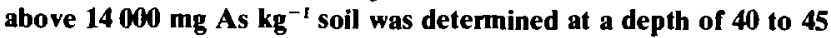
$\mathrm{cm}$. A sequential fractionation scheme, based on a soil $P$ fractionation, was developed to assess the chemical nature, and thus the potential bioavailability and mobility of As, at the sites. Soil As is separated into six fractions with (i) anion exchange resin, (ii) $\mathrm{NaHCO}_{3}$, (iii) $\mathrm{NaOH}$, (iv) $\mathrm{NaOH}$ following sonication, (v) $\mathrm{HCl}$, and (vi) $\mathrm{HCl} / \mathrm{HNO}_{2}$ Although substantial differences between sites and soil depths were present, some general trends were apparent. Most sites contained substantial concentrations of As in the two most labile fractions, indicating high potential for phytotoxicity and leaching. The bulk of the contaminant As at the sites seemed to be associated with soil amorphous $\mathrm{Fe}$ and $\mathrm{Al}$ minerals.
\end{abstract}

$\mathrm{F}$ ROM the turn of the century until the early 1950s. sodium arsenite was used extensively in cattle dips in Queensland and NSW, Australia, for controlling cattle ticks. Between 1920 and 1980, more than 1600 cattle dips were constructed in northeastern NSW alone (Vaughan, 1993; Barzi et al., 1996). The dips are constructed of concrete and are deep enough to completely immerse cattle as they are driven through the dip via entrance and exit ramps. During passage of stock through the dip, considerable splashing of the dip contents occur and the areas immediately surrounding the dips are often highly contaminated with As, with concentrations

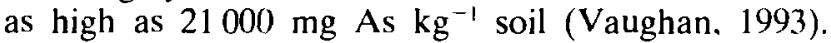
Population growth in northeastern NSW is increasing

R.G. McLaren. Department of Soil Science. P.O. Box 84. Lincoln University, Canterbury. New Zealand: R. Naidu, J. Smith and K.G. Tiller. CSIRO Division of Soils and the Cooperative Research Centre for Soil and Land Use Management. Private Mail Bag no. 2. Glen Osmond. S.A. 5064. Received 21 May 1997. "Corresponding author (mclaren@lincoln.ac.nz).

Published in J. Environ. Qual. 27:348-3.54 (1998). rapidly, and many former dip sites are now being encroached upon by urban developments, including residential housing. Such developments have raised concerns about possible harmful effects resulting from the residual As at these sites, including, for example, ingestion of contaminated soil by children or household pets, As toxicity to plants, and the potential release of As into surface and groundwaters. At some urban sites, the NSW Department of Agriculture is considering digging and storing contaminated soils in closed sheds. The Tweed Valley City Council recently expressed the possibility of storing $20000 \mathrm{~m}^{3}$ of soil in their region (Tweed Valley Council, 1996, personal communication).

Contamination of orchard soils with As-containing pesticides such as lead arsenate and various organoarsenical compounds has been studied in some detail (Woolson et al., 1971a; Merry et al., 1983; Veneman et al., 1983). However, there has been no comparable study of As contamination at cattle dip sites. In contrast to orchard locations, As contamination at dip sites is much more localized, and the source was predominantly sodium arsenite. The objective of this study was to examine the nature of As contamination at a range of former cattle dip sites in northeastern NSW, and develop techniques that might be useful for assessing the potential bioavailability and mobility of the As present in the contaminated soils.

It is generally recognized that total As concentration in the soil is not necessarily a good indicator of potential bioavailability or mobility. Several previous studies of As-contaminated soils have attempted to assess bioavailability using different extractants (Woolson et al.. 1971b; Johnston and Barnard, 1979; Lee and Low, 1990). For other soil contaminants, particularly trace metals. detailed characterizations are often carried out using sequential extraction techniques. However, the feasibility of using sequential extraction schemes designed for transition metals for fractionating soil As has been questioned (Gruebel et al., 1988). An alternative approach for As has been to use sequential extraction schemes

Abbreviations: AEM. anion exchange membrane: AAS, atomic absorption spectrophotometry; CCA. copper, chromium. and arsenic. 
designed to study the forms of $\mathrm{P}$ in soils. The chemistry of As in soils has apparent similarities with that of $P$ in that they both commonly form oxyanions in the $+\mathrm{V}$ oxidation state (O'Neill, 1990). In the 1970s, researchers used adaptations of the Chang and Jackson soil $P$ fractionation procedure (Chang and Jackson, 1957) to examine As in contaminated soils (Jacobs et al., 1970; Woolson et al., 1971a, 1973; Johnston and Barnard, 1979). However, it is recognized that the Chang and Jackson procedure presents many interpretational problems for soil P (Tiessen and Moir, 1993), and, by analogy, for soil As. An alternative P-fractionation scheme (Hedley et al., 1982) is now widely used in soil P studies. In this paper an adaptation of the Hedley et al. (1982) scheme is used to fractionate As in soils from contaminated cattle dip sites. It was assumed that although As was originally added to the dips as As(III), under the predominantly aerobic soil conditions at the sites, oxidation to $\mathrm{As}(\mathrm{V})$ would have occurred during the $40 \mathrm{yr}$ since As was last used.

\section{MATERIALS AND METHODS}

\section{Soil Sampling and Preparation}

Soils were sampled adjacent to cattle dip installations in northern NSW. At each site, two soil pits were located $1 \mathrm{~m}$ from the edge of the cattle dip, with the first pit $1.5 \mathrm{~m}$ from the point at which cattle would have entered the dip and the second pit 2 to $3 \mathrm{~m}$ further along the dip. Surface $(0-10 \mathrm{~cm})$ and subsurface $(20-40 \mathrm{~cm})$ soil samples were taken from each pit and then bulked to give single surface and subsoil samples from each site. Sampling depths were varied at some sites, to avoid inclusion of material from more than one recognizable soil horizon in a single sample. In some cases, more than two samples were taken to include material from other horizons, including some samples taken at depths $>40 \mathrm{~cm}$. The bulk samples were air-dried and ground to pass a $2 \mathrm{~mm}$ sieve. Some relevant properties of the samples are listed in Table 1.

\section{Total, Water-Extractable, and Acid Oxalate- Extractable Arsenic}

For total soil As, a 1-g sample was digested with $10 \mathrm{~mL}$ aqua regia $\left(5: 3 \mathrm{HCl} / \mathrm{HNO}_{3}\right)$ in a Milestone microwave digestion unit. Using $2 \mathrm{M} \mathrm{HCl}$, the resulting digest was transferred to a $25-\mathrm{mL}$ volumetric flask and made up to volume. The digest was then filtered through Whatman no. 42 filter paper.

For water-extractable As, a 5-g soil sample was weighed into a polypropylene centrifuge tube and shaken with $25 \mathrm{~mL}$ deionized water for $16 \mathrm{~h}$. The suspension was then centrifuged, and the supernatant solution filtered through a $0.45 \mu \mathrm{m}$ nylon filter.

For acid oxalate-extraction, a 1-g soil sample was weighed into a centrifuge bottle and $100 \mathrm{~mL}$ of oxalate reagent was added $(0.2 \mathrm{M}$ ammonium oxalate, $0.2 \mathrm{M}$ oxalic acid, $\mathrm{pH} 3)$. The suspension was shaken for $4 \mathrm{~h}$ in the dark and then filtered through no. 42 Whatman filter paper.

\section{Sequential Fractionation of Soil Arsenic}

Step 1: Anion exchange membrane-extractable As. A sample of soil $(2 \mathrm{~g})$ and a $62.5 \mathrm{~mm}$ by $25 \mathrm{~mm}$ strip of anion exchange membrane (AEM) (BDH Product 551642 2S) were suspended in $30 \mathrm{~mL}$ of deionized water in a polypropylene centrifuge tube and shaken for $24 \mathrm{~h}$. The AEM strip was then carefully removed from the suspension, washed with deionized water to remove any adhering soil particles and then placed in another tube containing $30 \mathrm{~mL}$ of $0.1 \mathrm{M} \mathrm{HCl}$. The tube containing the strip was then shaken for $1 \mathrm{~h}$ and As determined in the resulting solution.

Following removal of the AEM strip, the soil suspension was centrifuged and the supernatant solution decanted from the soil residue.

Step 2: Sodium bicarbonate-extractable As. The soil residue from Step 1 was resuspended in $30 \mathrm{~mL}$ of $\mathrm{NaHCO}_{3}(0.5 \mathrm{M}$, $\mathrm{pH} 8.5)$ and shaken for $16 \mathrm{~h}$. The sample was then centrifuged and the supernatant solution filtered through a $0.45 \mu \mathrm{m}$ nylon filter.

Step 3: Sodium hydroxide-extractable As. The soil residue from Step 2 was resuspended in $30 \mathrm{~mL}$ of $\mathrm{NaOH}(0.1 M)$ and

Table 1. Properties of soils at cattle dip sites.

\begin{tabular}{|c|c|c|c|c|c|c|c|c|}
\hline Site & Depth & pHt & Org. C $\neq$ & Oxalate Fe $\$$ & Oxalate Al\$ & Resin-Pq & Clay\# & Sand \\
\hline & cm & & $\%$ & 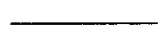 & 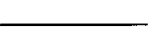 & $\mathbf{m g} \mathbf{k g}^{-1}$ & 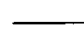 & $\ldots$ \\
\hline \multirow[t]{3}{*}{ Geraghty } & $0-10$ & 6.05 & 5.59 & 8.0 & 1.3 & 75.9 & 24.1 & 55.0 \\
\hline & $20-40$ & 6.99 & 1.25 & 10.5 & 1.4 & 57.0 & 38.7 & 43.1 \\
\hline & $40+$ & 6.87 & 2.14 & 19.7 & 2.7 & 82.9 & 31.7 & 40.2 \\
\hline \multirow{3}{*}{ Lindendale } & $0-6$ & 6.16 & 14.73 & 9.3 & 6.5 & 169.5 & 17.5 & $\mathbf{3 3 . 3}$ \\
\hline & $6-10$ & 5.71 & 1.56 & 3.8 & 4.3 & 151.2 & 30.5 & 48.3 \\
\hline & $20-40$ & 5.93 & 2.82 & 5.7 & 4.4 & 27.1 & 23.7 & 51.1 \\
\hline \multirow[t]{3}{*}{ Sandy Flat } & $0-8$ & 483 & 7.03 & 8.4 & 1.8 & 32.1 & 23.1 & 52.2 \\
\hline & $20-40$ & 4.97 & 1.54 & 1.5 & 0.2 & 45.0 & 8.1 & 87.9 \\
\hline & $40-45$ & 12.16 & 3.97 & 1.6 & 1.3 & 9.3 & 11.7 & 29.5 \\
\hline \multirow[t]{2}{*}{ Willow Bank } & $0-10$ & 5.65 & 5.39 & 14.3 & 3.5 & 26.9 & 42.3 & 22.0 \\
\hline & $20-40$ & 5.17 & 3.24 & 7.3 & 3.2 & 44.6 & 43.3 & 22.5 \\
\hline \multirow{2}{*}{ Lynwood } & $0-10$ & 5.70 & 6.69 & 11.1 & 4.5 & 89.2 & 30.9 & 25.7 \\
\hline & $20-40$ & 5.83 & 2.75 & 4.5 & 3.2 & 12.5 & 27.3 & 33.4 \\
\hline \multirow[t]{2}{*}{ Hetherington } & 0-10 & 5.48 & 1.11 & 1.1 & 0.3 & 105.2 & 6.9 & 88.3 \\
\hline & $20-40$ & 5.43 & 0.47 & 0.8 & 0.7 & 79.7 & 9.3 & 89.9 \\
\hline \multirow[t]{3}{*}{ Wagner } & $0-10$ & 5.57 & 5.75 & 9.8 & 1.0 & $\mathbf{7 2 . 1}$ & 27.9 & 48.6 \\
\hline & $15-25$ & 6.48 & 2.11 & 12.9 & 2.3 & 53.5 & 42.9 & 21.1 \\
\hline & $25-40$ & 6.33 & 1.35 & 7.7 & 2.1 & 22.3 & 46.7 & 23.2 \\
\hline \multirow[t]{2}{*}{ Ridges } & $0-10$ & 5.46 & 2.98 & 7.0 & 3.6 & 35.6 & 37.7 & 47.2 \\
\hline & $20-40$ & 5.93 & 3.30 & 6.4 & 6.0 & 19.7 & 36.9 & 30.5 \\
\hline \multirow{2}{*}{ Laurel } & $0-10$ & 5.85 & 5.30 & 8.5 & 2.9 & 41.9 & 31.9 & 41.8 \\
\hline & $20-40$ & 6.61 & 1.83 & 8.7 & 3.8 & 51.9 & ND & ND \\
\hline \multirow[t]{2}{*}{ Benaud } & 0-10 & 5.72 & 2.57 & 1.1 & 0.6 & 29.5 & 6.1 & 83.3 \\
\hline & $20-40$ & 6.18 & 0.53 & 0.4 & 0.0 & 26.7 & 8.5 & 87.6 \\
\hline \multirow[t]{2}{*}{ Zeus } & 0-10 & 5.45 & 4.47 & 5.1 & 1.1 & 40.6 & ND & ND \\
\hline & $20-40$ & 6.57 & 0.98 & 1.8 & 1.1 & 60.3 & ND & ND \\
\hline
\end{tabular}

† 1:5 water, $\ddagger$ Leco CNS analyzer; $\$$ Blakemore et al., 1987; If Step 1 in fractionation; \# Pipette method; ND = not determined. 
shaken for $16 \mathrm{~h}$. The suspension was then centrifuged and the supernatant solution filtered through Whatman no. 42 filter paper.

Step 4: Sonicated/sodium hydroxide-extractable As. The soil residue from Step 3 was resuspended in $30 \mathrm{~mL}$ of $\mathrm{NaOH}$ $(0.1 M)$ and was then dispersed for $3 \mathrm{~min}$ with an ultrasonic probe (Branson sonifier, model B-30, operated at $20 \mathrm{kHz}$, meter reading 20). The suspension was then shaken for $16 \mathrm{~h}$. centrifuged, and filtered through Whatman no. 42 filter paper.

Step 5: Hydrochloric acid-extractable As. The soil residue from Step 4 was resuspended in $30 \mathrm{~mL}$ of $\mathrm{HCl}(1 M)$ and shaken for $16 \mathrm{~h}$. The suspension was then centrifuged and the supernatant solution filtered through a $0.45 \mu \mathrm{m}$ nylon filter. The soil residue was oven-dried at $60^{\circ} \mathrm{C}$ for $48 \mathrm{~h}$ and then finely ground in an agate mortar.

Step 6: Residual Arsenic. Arsenic in the dried and ground residue from Step 5 was determined as for total soil As.

\section{Analytical Methods}

All the above extractions involved shaking for the required time on an end-over-end shaker, and all centrifuging was carried out at $10000 \mathrm{~g}$ for $10 \mathrm{~min}$. If possible, centrifuged extracts were filtered through $0.45 \mu \mathrm{m}$ nylon filters, however, with some extracts this was not practical and so Whatman no. 42 paper filters were used. Arsenic in the filtrates was determined by direct atomic absorption spectrophotometry (AAS) using a nitrous oxide-acetylene flame, or after hydride generation using an air-acetylene flame. Iron and aluminium in the oxalate filtrates were also determined by AAS (Blakemore et al.. 1987). All analyses were carried out in duplicate and all results shown are mean values.

\section{RESULTS AND DISCUSSION}

Total As concentrations in uncontaminated surface soils worldwide range from $<0.1$ to $95 \mathrm{mg} \mathrm{kg}^{-1}$ with mean values generally $<20 \mathrm{mg} \mathrm{kg}^{-1}$ (Kabata-Pendias and Pendias, 1992). There are very few data available for
Australian soils, although Merry et al. (1983) reported a mean As concentration of $3.9 \mathrm{mg} \mathrm{kg}^{-1}$ for 15 South Australian surface soils and $0.60 \mathrm{mg} \mathrm{kg}^{-1}$ for six soils from Tasmania. In comparison to such values, surface and subsoils at all the cattle dip sites sampled are heavily contaminated with As (Table 2). Surface soil concentrations range from 29.8 to $3542 \mathrm{mg} \mathrm{As} \mathrm{kg}{ }^{-1}$ soil and subsoil concentrations from 56.7 to $2282 \mathrm{mg} \mathrm{kg}^{-1}$. At all sites there has been an apparent substantial downward movement of As, although the pattern of distribution with depth varies between sites. Because of the permanent and waterproof nature of dip construction at these sites, it is extremely unlikely that any of the subsoil As contamination has resulted underground lateral flow from the dips. Seven of the sites (Geraghty, Sandy Flat, Willow Bank, Lynwood, Heatherington, Benaud, and Zeus) show much higher concentrations in the subsoil compared to the surface (Table 2). With the exception of Geraghty and Sandy Flat, these sites have relatively uniform soil profiles and in the case of the Hetherington and Benaud sites are extremely sandy in texture and have very low oxide concentrations (Table 1). At the Geraghty site, the major accumulation of As occurs below $40 \mathrm{~cm}$, coinciding with a marked increase in iron (and $\mathrm{Al}$ ) oxides at this depth in the soil profile (Table 1). The Ridges and Laurel sites are the only sites where As concentrations are highest in the surface horizons. These two sites also have relatively uniform soil profiles, but compared to Hetherington, Benaud and Zeus sites in particular, are much less sandy and have much higher $\mathrm{Fe}$ and $\mathrm{Al}$ oxide concentrations (Table 1). At the Wagner and Lindendale sites there were peak accumulations of As in the middle horizons sampled (Wagner, $15-25 \mathrm{~cm}$; Lindendale $6-10 \mathrm{~cm}$, Table 2). In both cases, these accumulations correspond with an increase in ox-

Table 2. Total and extractable soil As concentrations (mg As $\mathrm{kg}^{-1}$ soil).

\begin{tabular}{|c|c|c|c|c|c|c|c|c|c|c|c|}
\hline \multirow[b]{2}{*}{ Site depth } & & \multicolumn{7}{|c|}{ As fractionation } & \multirow[b]{2}{*}{ Total As } & \multirow{2}{*}{$\begin{array}{c}\text { Water- } \\
\text { extractable } \\
\text { As }\end{array}$} & \multirow{2}{*}{$\begin{array}{c}\text { Oxalate- } \\
\text { extractable } \\
\text { As } \\
\end{array}$} \\
\hline & & Resin & $\mathrm{NaHCO}_{3}$ & $\mathrm{NaOH}(1)$ & $\mathrm{NaOH}(2)$ & HCl & Residual & $\begin{array}{l}\text { Sum of } \\
\text { fractions }\end{array}$ & & & \\
\hline & $\mathrm{cm}$ & & & & & & & & & & \\
\hline \multirow[t]{3}{*}{ Geraghty } & 0-10 & 95 & 87 & 687 & 189 & 371 & 259 & 1690 & 1920 & 22.4 & 1210 \\
\hline & $10-40$ & 133 & 92 & 499 & 145 & 95 & 335 & 1300 & 1220 & 22.4 & 883 \\
\hline & $\mathbf{4 0}+$ & 220 & 287 & 1460 & 366 & 342 & 827 & 3500 & 3550 & 36.7 & 2540 \\
\hline \multirow[t]{3}{*}{ Lindendale } & $0-6$ & 4 & 10 & 27 & 71 & 54 & 109 & 275 & 380 & 1.0 & 133 \\
\hline & $6-10$ & 46 & 84 & 556 & 261 & 0 & 566 & 1510 & 1480 & 10.0 & 671 \\
\hline & $20-40$ & 1 & 0 & 43 & 19 & 0 & 8 & 71 & 103 & 0.0 & 24 \\
\hline \multirow[t]{3}{*}{ Sandy Flat } & $0-8$ & 4 & 15 & 208 & 71 & 26 & 88 & 412 & 446 & 0.9 & 267 \\
\hline & $20-40$ & 17 & 20 & 182 & 38 & 13 & 39 & 309 & 310 & 7.6 & 265 \\
\hline & $40-45$ & 52 & 10400 & 974 & 249 & 1950 & 458 & 14100 & 14800 & 1.2 & 4310 \\
\hline \multirow[t]{2}{*}{ Willow Bank } & $0-10$ & 5 & 22 & 277 & 124 & 0 & 177 & 605 & 658 & 0.2 & 304 \\
\hline & $20-40$ & 6 & 153 & 1110 & 382 & 0 & 702 & 2350 & 2230 & 1.1 & 1160 \\
\hline \multirow[t]{2}{*}{ Lynwood } & 0-10 & 3 & $\mathbf{3}$ & 90 & 45 & 2 & 90 & 233 & 276 & 0.3 & 128 \\
\hline & $20-40$ & 47 & 127 & 1070 & 353 & 0 & 575 & 2170 & 2100 & 7.2 & 830 \\
\hline \multirow[t]{2}{*}{ Hetherington } & 0-10 & 1 & 0 & 12 & 3 & 2 & 0 & 18 & 30 & 0.6 & 12 \\
\hline & $20-40$ & 3 & 0 & 36 & 9 & 3 & 9 & 60 & 57 & 1.5 & 33 \\
\hline \multirow[t]{3}{*}{ Wagner } & 0-10 & 58 & 55. & 778 & 242 & 276 & 109 & 1520 & 1440 & 13.1 & 1180 \\
\hline & $15-25$ & 180 & $186^{\circ}$ & 1020 & 179 & 209 & 357 & 2130 & 2050 & 35.7 & 1840 \\
\hline & $25-40$ & 73 & 80 & 413 & 74 & 28 & 167 & 835 & 844 & 14.6 & 707 \\
\hline \multirow[t]{2}{*}{ Ridges } & 0-10 & 33 & 127 & 869 & 247 & 38 & 548 & 1860 & 1630 & 2.6 & 1080 \\
\hline & $20-40$ & 3 & 5 & 336 & 109 & 0 & 130 & 583 & 629 & 0.1 & 238 \\
\hline \multirow[t]{2}{*}{ Laurel } & 0-10 & 104 & 130 & 1050 & 540 & 49 & 1530 & 3400 & 3540 & 8.0 & 1410 \\
\hline & $20-40$ & 102 & 144 & 936 & 405 & 19 & 942 & 2550 & 2280 & 2.2 & 1070 \\
\hline \multirow[t]{2}{*}{ Benaud } & 0-10 & 2 & 13 & 3 & 5 & 5 & 3 & 31 & 37 & 0.5 & 15 \\
\hline & $20-40$ & $\overline{5}$ & 13 & 38 & 2 & 2 & 6 & 66 & 88 & 1.8 & 47 \\
\hline \multirow[t]{2}{*}{ Zeus } & 0-10 & 7 & 9 & 92 & 17 & 21 & 27 & 173 & 165 & 1.7 & 189 \\
\hline & $20-40$ & 12 & 7 & 139 & 14 & 30 & 13 & 215 & 232 & 2.1 & 222 \\
\hline
\end{tabular}


ide iron and/or clay concentrations in the profile (Table 1).

The most contaminated soil occurred at Sandy Flat. Although the 0 to $8 \mathrm{~cm}$ and 20 to $40 \mathrm{~cm}$ samples showed moderate contamination compared to some of the other sites (Table 2), a sample taken from 40 to $45 \mathrm{~cm}$ had an As concentration of $14760 \mathrm{mg} \mathrm{kg}^{-1}$ (Table 2). The upper part of the soil profile at this site is very sandy and the 20 to $40 \mathrm{~cm}$ horizon in particular has very low $\mathrm{Fe}$ and $\mathrm{Al}$ oxide concentrations (Table 1). However, the 40 to $45 \mathrm{~cm}$ horizon has some very unusual properties that could account for the marked As accumulation in this layer. The horizon is far less sandy than the horizons above and has an extraordinary high $\mathrm{pH}$ of 12.16 (Table 1). The $21 \% \mathrm{CaCO}_{3}$, present in this horizon could not on its own account for the high $\mathrm{pH}$, although the presence of $\mathrm{Ca}(\mathrm{OH})_{2}$ could. Apart from $\mathrm{CaCO}_{3}$, the mineralogy appears to be dominated by poorly crystalline kaolin with traces of quartz. Analysis of soil solution from this horizon and speciation modelling using MINTEQA2 (Allison and Brown, 1995) suggested that As

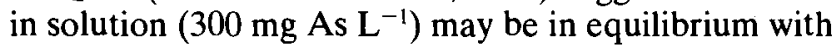
calcium arsenate. This particular horizon remains something of an enigma.

Downwards movement of As through the soil profile has been recorded in orchard soils contaminated with lead arsenate pesticide (Merry et al., 1983; Peryea and Creger, 1994; Elfving et al., 1994) or sodium arsenite herbicide (Tammes and de Lint, 1969). In such situations both the level of As contamination and degree of leaching were much less than at the cattle dip sites. Comparable levels of As contamination and leaching to those found at the dip sites have been recorded in coarsetextured soil contaminated with copper, chromium, and arsenic (CCA) timber preservative solution (Armishaw et al., 1994).

The substantial downwards movement of As at the cattle dip sites results from several factors. During cattle dipping, the soil surrounding the dip quickly becomes saturated with fluid from the dip as the cattle splash through. In such a situation, As is likely to be leached downwards via preferential flow, particularly in coarsetextured or well-structured soils (McLaren et al., 1994; Carey et al., 1996). McLaren et al. (1994) also demonstrated that As leaching is enhanced by short contact periods with the soil. This would certainly be the case during cattle dipping where the continuous input of Ascontaining liquid from the dip would ensure optimum leaching conditions. Although use of As at the dip sites was discontinued in the early 1950 s, cattle dipping at many of the sites has continued using a variety of organic pesticides. This would have ensured that large volumes of water would still have passed through the soil at frequent intervals, with the potential to cause further As leaching during the past $40 \mathrm{yr}$. In addition, some of the organic chemicals used since the 1950 s have been stabilized in the dips by the addition of substantial amounts of phosphate (Kerryn McDougall, 1995, personal communication). Addition of phosphate can enhance As leaching in soils (Davenport and Peryea, 1991; Melamed et al., 1995; Peryea and Kammereck, 1997).
At many of the dip sites, soil concentrations of resinextractable phosphate were present at concentrations much higher than those found in normal agricultural soils (Table 1). Subsequent laboratory leaching column studies with phosphate solutions have shown significant leaching of As from the contaminated soils (R. Naidu, 1996, unpublished data).

Although total soil As concentration gives a good indication of the extent of soil contamination, it is not a reliable indicator of potential toxicity to plants (Vaughan, 1993), or presumably of potential for As leaching. Sequential extraction of soil As helps to differentiate between As that is readily labile and that which is bound strongly by the soil. The fractionation used in this study consists of six separate steps and thus, as with any such technique, has the potential for considerable combined experimental and analytical errors. To check the procedure, the sums of the As concentrations determined in the six individual fractions were compared with the single determinations of total As for the dip site samples (Table 2). There was extremely good agreement between the two sets of values $\left(\mathrm{As}_{\text {sum }}=\right.$ $1.02 \mathrm{As}_{\text {total }}-9.03, r^{2}=0.99$ ).

Although no fractionation scheme can be considered $100 \%$ effective in distinguishing between different forms of an element, by analogy with the $P$ fractionation scheme of Hedley et al. (1982) as discussed by Tiessen and Moir (1993), the forms of As present in the six fractions are designated as follows:

1. Resin-extractable As: freely exchangeable As.

2. $\mathrm{NaHCO}_{3}$-extractable As: nonexchangeable but readily labile As associated with soil mineral surfaces.

3. NaOH-extractable As: As held more strongly by chemisorption to $\mathrm{Fe}$ and $\mathrm{Al}$ components of soil surfaces.

4. Sonication $/ \mathrm{NaOH}$-extractable As: As held at the internal surfaces of soil aggregates.

5. HCl-extractable As: Ca-associated As.

6. Residual As: Highly recalcitrant As.

It is assumed that As is associated predominantly with inorganic soil constituents. Organic forms of As do not appear to compose an appreciable proportion of total soil As (Johnson and Hiltbold, 1969).

Considerable variation occurs between the sites and soil depths in the amounts and proportions of As present in individual fractions (Tables 2 and 3). However, in spite of this variation, some general trends are apparent. The most labile As fraction (resin-extractable As) accounts for $<10 \%$ of the total soil As (mean $3.9 \%$, Table 3 ). In most soils, relatively small proportions of total As are also extracted in the second fraction $\left(\mathrm{NaHCO}_{3}-\right.$ extractable As). However the 40 to $45 \mathrm{~cm}$ sample from Sandy Flat has nearly $74 \%$ of its total As in this fraction. The unusual properties of this sample have been commented on above. The Benaud site samples also have a high proportion of their total As in the $\mathrm{NaHCO}_{3}$ extractable fraction $(20-40 \%$, Table 3$)$. This soil at this site is extremely sandy and has very low $\mathrm{Fe}$ and $\mathrm{Al}$ oxide concentrations and thus probably has a much lower As- 
Table 3. Proportions of As in individual fractions ( $\%$ sum of all fractions).

\begin{tabular}{|c|c|c|c|c|c|c|c|}
\hline Site & Depth & $\begin{array}{c}\text { Resin } \\
\text { As }\end{array}$ & $\begin{array}{c}\mathrm{NaHCO}_{1} \\
\mathrm{As}\end{array}$ & $\begin{array}{c}\mathrm{NaOH}(1) \\
\mathrm{As}\end{array}$ & $\begin{array}{c}\mathrm{NaOH}(2) \\
\mathrm{As}\end{array}$ & $\begin{array}{c}\mathrm{HCl} \\
\text { As }\end{array}$ & $\begin{array}{c}\text { Residual } \\
\text { As }\end{array}$ \\
\hline & $\mathrm{cm}$ & & & & & & \\
\hline \multirow[t]{3}{*}{ Geraghty } & $0-10$ & 5.6 & 5.2 & 40.7 & 11.2 & 22.0 & 15.3 \\
\hline & $20-40$ & 10.2 & 7.1 & 38.4 & 11.2 & 7.4 & 25.8 \\
\hline & $40+$ & 6.3 & 8.2 & 41.7 & 10.5 & 9.8 & 23.6 \\
\hline \multirow[t]{3}{*}{ Lindendale } & $0-6$ & 1.4 & 3.6 & 9.9 & 25.9 & 19.5 & 39.7 \\
\hline & $6-10$ & 3.0 & 5.6 & 36.7 & 17.3 & 0.0 & 37.4 \\
\hline & $20-40$ & 0.9 & 0.0 & 60.5 & 26.6 & 0.5 & 11.4 \\
\hline \multirow[t]{3}{*}{ Sandy Flat } & $0-8$ & 0.9 & 3.7 & 50.5 & 17.3 & 6.3 & 21.4 \\
\hline & $20-40$ & 5.6 & 6.4 & 58.8 & 12.2 & 4.3 & 12.6 \\
\hline & $40-45$ & 0.4 & 73.9 & 6.9 & 1.8 & 13,8 & 3.3 \\
\hline \multirow[t]{2}{*}{ Willow Bank } & $0-10$ & 0.8 & 3.6 & 45.8 & 20.6 & 0.0 & 29.2 \\
\hline & $20-40$ & 0.3 & 6.5 & 47.2 & 16.2 & 0.0 & 29.8 \\
\hline \multirow[t]{2}{*}{ Lynwood } & $0-10$ & 1.1 & 1.2 & 38.7 & 19.5 & 0.7 & 38.8 \\
\hline & $20-40$ & 2.2 & 5.8 & 49.3 & 16.3 & 0.0 & 26.5 \\
\hline \multirow[t]{2}{*}{ Hetherington } & $0-10$ & 5.8 & 0.0 & 69.1 & 15.4 & 9.6 & 0.0 \\
\hline & $20-40$ & 4.2 & 0.0 & 61.2 & 14.7 & 5.3 & 14.6 \\
\hline \multirow[t]{3}{*}{ Wagner } & 0-10 & 3.8 & 3.6 & 51.3 & 15.9 & 18.2 & 7.2 \\
\hline & $15-25$ & 8.4 & 8.7 & 48.0 & 8.4 & 9.8 & 16.7 \\
\hline & $25-40$ & 8.7 & 9.6 & 49.5 & 8.9 & 3.3 & 20.0 \\
\hline \multirow[t]{2}{*}{ Ridges } & $0-10$ & 1.8 & 6.8 & 46.7 & 13.3 & 2.0 & 29.5 \\
\hline & $20-40$ & 0.5 & 0.8 & 57.7 & 18.7 & 0.0 & 22.3 \\
\hline \multirow[t]{2}{*}{ Laurel } & $0-10$ & 3.1 & 3.8 & $\mathbf{3 0 . 8}$ & 15.9 & 1.4 & $\mathbf{4 5 . 0}$ \\
\hline & $20-40$ & 4.0 & 5.6 & 36.7 & 15.9 & 0.7 & 37.0 \\
\hline \multirow[t]{2}{*}{ Benaud } & $0-10$ & 4.9 & 42.3 & 9.7 & 16.2 & 16.1 & 10.8 \\
\hline & $20-40$ & 9.1 & 20.2 & 57.8 & 2.6 & 2.7 & 8.8 \\
\hline \multirow[t]{2}{*}{ Zeus } & $0-10$ & 3.8 & 5.4 & 53.7 & 9.7 & 11.9 & 15.4 \\
\hline & $20-40$ & 5.7 & 3.5 & 64.7 & 6.5 & 13.7 & 6.0 \\
\hline Mean values & & 3.9 & 9.3 & 44.7 & 14.2 & 6.9 & 21.1 \\
\hline
\end{tabular}

retention capacity than soil from most other sites. The relatively low proportions of resin and $\mathrm{NaHCO}_{3}$-extractable As at most sites does not mean that As toxicity or mobility is unlikely to be a problem. The high total As concentrations ensure that the labile forms of As are often well above the levels likely to cause phytotoxicity (Sheppard, 1992). In addition, the relatively high amounts of As in labile forms at depth in some soil profiles, suggests a significant potential for further leaching.

Resin-extractable As was highly correlated with water-soluble As (Fig. 1), with water-soluble As concentrations being approximately $15 \%$ of resin-extractable As concentrations (Table 2). Resin-extractable As may have value as an indicator of potential bioavailability and/or mobility of contaminant As in soil. The higher concentrations of As extracted by the resin compared to water can be a distinct advantage as far as analysis of As is concerned.

At most of the sites, the bulk of the As was present in the $\mathrm{NaOH}$-extractable fractions with a mean $44.7 \%$ in the first extraction and a further $14.2 \%$ aitter sonication. The As in these fractions is likely to be associated with $\mathrm{Fe}$ and $\mathrm{Al}$ oxide materials present in the soils. Arsenic is known to be strongly sorbed by such materials (Huang, 1975; Anderson et al., 1975; Goldberg, 1986; Vaughan, 1993), and previous fractionation studies of As-contaminated soils have also found a predominance of Fe- and Al-bound forms of As (Jacobs et al., 1970; Woolson et al., 1971a; Woolson et al., 1973). Relatively small proportions of As were found in the $\mathrm{HCl}$-extractable fraction overall (mean $6.9 \%$ ). However, for some individual samples, up to $22 \%$ of the total As was present in this fraction (Table 3 ). The final fraction contained on average $21.1 \%$ of the total As (range $0-45 \%$ ).
The relative difficulty in extracting this fraction of As, suggests that it should be considered to be extremely tightly bound and thus very unlikely to be bioavailable or mobile. It should be noted, that at some sites, for example Wagner (Table 3), the proportion of As associated with this fraction increases with soil depth. At such sites, it would appear that downward movement of mobile forms of As has been followed by transformation into relatively recalcitrant forms.

Further examination of the fractionation data showed

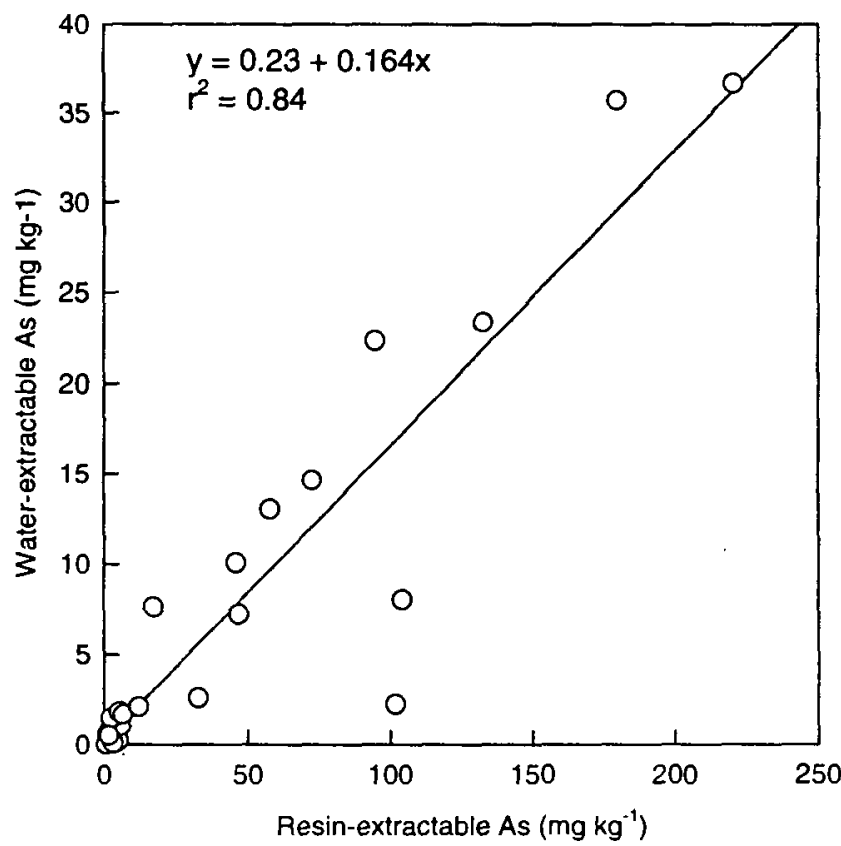

Fig. 1. Relationship between water-extractable $A$ s and resin-extractable As. 
Table 4. Linear correlation coeficients $(r)$ between As concentrations in individual fractions and some soil properties.

\begin{tabular}{|c|c|c|c|c|c|c|c|c|c|c|}
\hline & $\underset{\mathrm{As}}{\mathrm{NaHCO}_{3}-}$ & $\underset{\mathrm{As}}{\mathrm{NaOH}(1)}$ & $\underset{\mathrm{As}}{\mathrm{NaOH}(2)-}$ & HCl-As & $\begin{array}{c}\text { Residual } \\
\text { As }\end{array}$ & $\begin{array}{c}\text { Total } \\
\text { As }\end{array}$ & $\begin{array}{c}\text { Oxalate- } \\
\text { Fe }\end{array}$ & $\begin{array}{c}\text { Oxalate- } \\
\text { Al }\end{array}$ & $\begin{array}{l}\text { Soil } \\
\text { pH }\end{array}$ & $\begin{array}{c}\text { Organic } \\
\text { C }\end{array}$ \\
\hline $\begin{array}{l}\text { Resin-As } \\
\text { NaHCO }{ }_{3} \text {-As } \\
\text { NaOH(1)-As } \\
\text { NaOH(2)-As } \\
\text { HCl-As } \\
\text { Residual As } \\
\text { Total As }\end{array}$ & $0.85^{* * *}$ & $\begin{array}{l}0.74^{* * * *} \\
0.94^{* * * *}\end{array}$ & $\begin{array}{l}0.56^{* *} \\
0.79^{* * *} \\
0.90^{* * *}\end{array}$ & $\begin{array}{l}0.71 * * * \\
0.53 * * \\
0.51 * * \\
0.29\end{array}$ & $\begin{array}{l}0.56^{* *} \\
0.75^{* * *} \\
0.80^{* * *} \\
0.95^{* * *} \\
0.16\end{array}$ & $\begin{array}{l}0.77^{* * *} \\
0.91^{* * *} \\
0.96^{* * *} \\
0.94^{* * *} \\
0.52^{* *} \\
0.91^{* * *}\end{array}$ & $\begin{array}{l}0.65^{* * *} \\
0.61^{* *} \\
0.57^{* *} \\
0.45^{*} \\
0.56^{* *} \\
0.39 \\
0.59 * *\end{array}$ & \begin{tabular}{r|}
-0.03 \\
0.12 \\
0.17 \\
0.30 \\
-0.16 \\
0.28 \\
0.20
\end{tabular} & $\begin{array}{l}0.66^{* * *} \\
0.43^{*} \\
0.28 \\
0.17 \\
0.37 \\
0.23 \\
0.33\end{array}$ & $\begin{array}{r}-0.18 \\
-0.18 \\
-0.11 \\
0.02 \\
0.12 \\
-0.03 \\
-0.03\end{array}$ \\
\hline
\end{tabular}

$*, * *, * * * P<0.05,0.01,0.001$.

that the amounts of As in the individual fractions were generally strongly correlated with each other and with total As concentrations (Table 4). (As a result of its anomalously high As concentration and the unusual properties of the Sandy Flat 40 to $45 \mathrm{~cm}$ sample, the data for this horizon was not included in the correlations.) Of all the fractions, $\mathrm{HCl}$-extractable As showed the weakest correlations with other fractions. In spite of the large variation in the degree of As contamination between sites, total As and the amounts of As in individual fractions were significantly correlated with oxalateextractable $\mathrm{Fe}$ (with the exception of residual As). There were no significant correlations with soil organic $C$ or oxalate-extractable $\mathrm{Al}$. The significant correlations between the two most labile fractions and soil pH (Table 4) may reflect reduced As sorption with increasing $\mathrm{pH}$, and consequent increases in the more weakly bound forms of soil As. Multiple regression analysis indicated that a high proportion of the variation in resin-extractable As concentrations could be explained by the regression:

$$
\begin{aligned}
\text { Resin-extractable As }= & 0.035(\text { Total As })+50.4(\mathrm{pH}) \\
& -289\left(r^{2}=0.78\right)
\end{aligned}
$$

In addition to the As determination in the six fractions described above, the oxalate extracts used for soil oxide

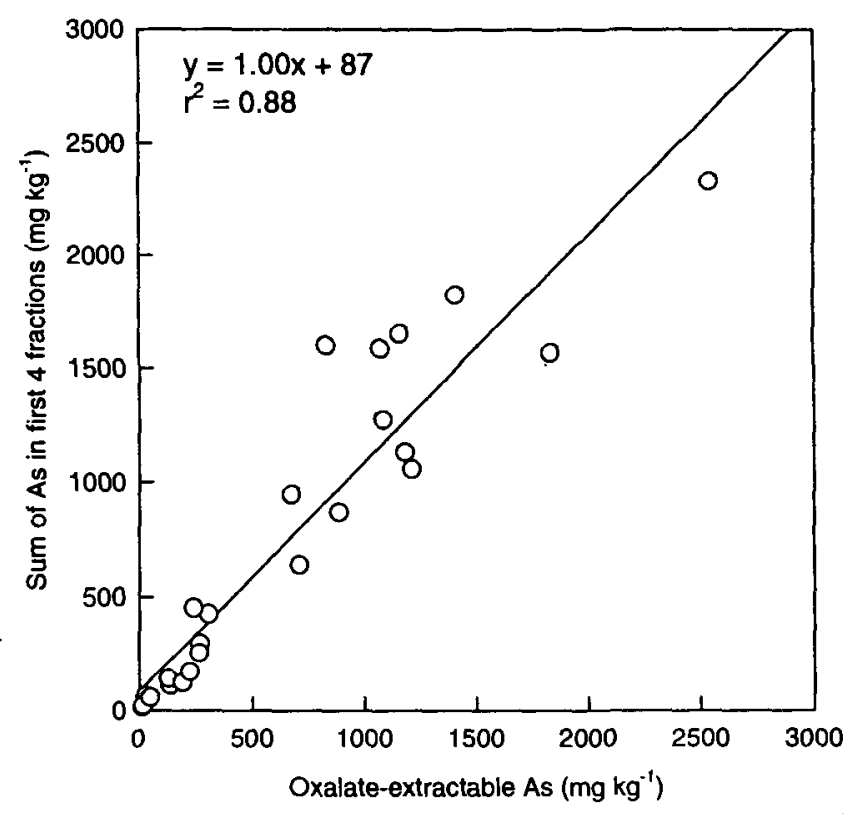

Fig. 2. Relationship between oxalate-extractable As and the sum of As concentrations in fractions 1 to 4 . determinations were also analyzed for As, thus giving a direct measure of As associated with the extracted $\mathrm{Fe}$ and $\mathrm{Al}$ (Table 2). There was an extremely close correlation (almost 1:1) between oxalate-extractable As and the sum of the As in the first four fractions of the sequential extraction scheme (Fig. 2). The oxalate reagent used is considered to extract only short-range order (amorphous) materials, thus the As extracted can be assumed to be associated predominantly with these types of $\mathrm{Fe}$ (and $\mathrm{Al}$ ) minerals. It seems likely that the As present in the first four fractions as determined by the sequential extraction scheme are not really completely separate pools, but represent a continuum of $\mathrm{Fe}$ - and $\mathrm{Al}$-associated As with increasing strength of bonding with the mineral surfaces.

\section{CONCLUSIONS}

The results obtained from this study demonstrate a considerable degree of soil contamination with As at the cattle dip sites examined. Although the actual areas of land contaminated are relatively small, restricted to the immediate area surrounding the cattle dip, the high level of contamination and downwards movement of As are significant causes for concern. Redevelopment of the sites for other uses will require the removal or remediation of substantial volumes of soil. The high concentrations of As in the most labile fractions, resinextractable and $\mathrm{NaHCO}_{3}$-extractable, are of particular concern. The sequential fractionation scheme for As, based on the $P$ fractionation, appears to be a useful method for investigating the chemical nature of contaminant As in soil. Resin-extractable As in particular might provide a good index of potential As bioavailability and mobility. The results from the study suggest that the bulk of the As present at the cattle dip sites is associated with the amorphous $\mathrm{Fe}$ (and $\mathrm{Al}$ ) minerals in the soils.

\section{ACKNOWLEDGMENTS}

The senior author would like to acknowledge the Sir Frederick McMaster Trust for the award of a research fellowship during which this study was carried out at the CSIRO Division of Soils, Adelaide. The authors also thank Kerryn McDougall of New South Wales Agriculture, Wollongbar for assistance in location and sampling of the cattle dip sites.

\section{REFERENCES}

Allison, J.D., and D.S. Brown. 1995. MINTEQA2/PRODEFA2-A geochemical speciation model and interactive preprocessor. p. 241252. In R.H. Loeppert et al. (ed.) Chemical equilibrium and reaction models. SSSA Spec. Publ. 42. SSSA and ASA, Madison, WI. 
Anderson. M.A., J.F. Ferguson, and J. Gavis. 1975. Arsenate adsorption on amorphous aluminium hydroxide. J. Colloid Interface Sci. 54:391-399.

Armishaw, R.F., A.G. Fricker. and G.A. Fenton. 1994. Soil and groundwater studies at some CCA timber treatment sites. Water and Wastes in N.Z., no. 78. March, p. 44-48.

Barzi. F., R. Naidu, and M.J. McLaughlin. 1996. Contaninants and the Australian soil environment. p. 451-484. In R. Naidu et al. (ed.) Contaminants and the soil environment in the AustralasiaPacific region. Kluwer Academic Press. Dordrecht. the Netherlands.

Blakemore. L.C., P.L. Searle. and B.K. Daly. 1987. Methods for chemical analysis of soils. NZ Soil Bureau Scientific Rep. 80. New Zealand Soil Bureau, Lower Hutt, NZ.

Carey, P.L., R.G. McLaren, K.C. Cameron, and J.R. Sedcole. 1996. Leaching of copper, chromium, and arsenic through some freedraining New Zealand soils. Aust. J. Soil Res, 34:583-597.

Chang, S.C., and M.L. Jackson. 1957. Fractionation of soil phosphorus. Soil Sci. 84:133-144.

Davenport. J.R., and F.J. Peryea. 1991. Phosphate fertilizers influence leaching of lead and arsenic in a soil contaminated with lead arsenate. Water Air Soil Pollut. 57-58:101-110.

Elfving, D.C., K.R. Wilson, J.G. Ebel Jr., K.L. Manzell, W.H. Gutenmann, and D.L. Lisk. 1994. Migration of lead and arsenic in old orchard soils in the Georgian Bay region of Ontario. Chemosphere 29:407-413.

Goldberg, S. 1986. Chemical modeling of arsenate adsorption on aluminium and iron oxide minerals. Soil Sci. Soc. Am. J. 50:1 154-1157.

Gruebel, K.A., J.A. Davis, and J.O. Leckie. 1988. The feasibility of using sequential extraction techniques for arsenic and selenium in soils and sediments. Soil Sci. Soc. Am. J. 52:390-397.

Hedley, M.J.. J.W.B. Stewart. and B.S. Chauhan. 1982. Changes in inorganic and organic soil phosphorus fractions induced by cultivation practices and by laboratory incubations. Soil Sci. Soc. Am. J. 46:970-976.

Huang, P.M. 1975. Retention of arsenic by hydroxy-aluminium on surfaces of micaceous mineral colloids. Soil Sci. Soc. Am. J. 39: 271-274.

Jacobs, L.W., J.K. Syers, and D.R. Keeney. 1970. Arsenic sorption by soils. Soil Sci. Soc. Am. Proc. 34:750-754.

Johnson, L.R., and A.E. Hiltbold. 1969. Arsenic content of soil and crops following use of methanearsonate herbicides. Soil Sci. Soc. Am. Proc. 33:279-282.

Johnston. S.E., and W.M. Barnard. 1979. Comparative effectiveness of fourteen solutions for extracting arsenic from four western New York soils. Soil Sci. Soc. Am. Proc. 43:304-308.

Kabata-Pendias, A., and H. Pendias. 1992. Trace elements in soils and plants. CRC Press, Boca Raton, FL.

Lee. C.K.. and K.S. Low. 1990. EDTA extractable arsenic in relation to available forms in soil. Pertanika 13:261-265.

McLaren. R.G.. P.L. Carey. K.C. Cameron, J.A. Adams, and J.R Sedcole. 1994. Effect of soil properties and contact period on the leaching of copper, chromium and arsenic through undisturbed soils. p. 156-169. In Trans. 15th World Congress of Soil Science. Vol. 3a. Int. Soc. Soil Sci. 1994. ISSS, Mexico.

Melamed, R., J.J. Jurinak. and L.M. Dudley. 1995. Effect of adsorbed phosphate on transport of arsenate through an oxisol. Soil Sci. Soc. Am. J. 59:1289-1294

Merry. R.H. K.G. Tiller and A.M. Alston. 1983. Accumulation of copper, lead and arsenic in some Australian orchard soils. Aust. J. Soil. Res. 21:549-561.

O'Neill, P. 1990. Arsenic. p. 83-99. In B.J. Alloway (ed.) Heavy metals in soils. John Wiley and Sons. New York.

Peryea. F.J., and T.L. Creger. 1994. Vertical distribution of lead and arsenic in soils contaminated with lead arsenate pesticide residues. Water Air Soil Pollut. 78:297-306.

Peryea, F.J., and R. Kammereck. 1997. Phosphate-enhanced movement of arsenic out of lead arsenate-contaminated topsoil and through uncontaminated subsoil. Water Air Soil Pollut. 93:243-254.

Sheppard, S.C. 1992. Summary of phytotoxic levels of soil arsenic. Water Air Soil Pollut. 64:539-550.

Tammes, P.M., and M.M. de Lint. 1969. Leaching of arsenic from soil. Neth. J. Agric. Sci. 17:128-132.

Tiessen, H., and J.O. Moir. 1993. Characterization of available $\mathrm{P}$ by sequential extraction. p. 75-86. In M.R. Carter (ed.) Soil sampling and methods of analysis. Lewis Publ., Boca Raton, FL

Vaughan, G.T. 1993. The environmental chemistry and fate of arsenical pesticides in cattle tick dip sites and banana land plantations. CSIRO Division of Coal Industry, Centre for Advanced Analytical Chemistry, Investigation Rep. CET/LHIRI48, NSW, Australia.

Veneman, P.L.M., J.R. Murray, and J.H. Baker. 1983. Spatial distribution of pesticide residues in a former apple orchard. J. Environ. Qual. 12:101-104.

Woolson, E.A., J.H. Axley, and P.C. Kearney. 1971a. The chemistry and phytotoxicity of arsenic in soils: I. Contaminated field soils. Soil Sci. Soc. Am. Proc. 35:938-943.

Woolson, E.A.. J.H. Axley, and P.C. Kearney. 1971b. Correlation between available soil arsenic, estimated by six methods, and response of corn (Zea mays L.). Soil Sci. Soc. Am. Proc. 35:101-105. 